\title{
Control of the intestinal flora by means of antibacterial drugs in surgery of the colon
}

\author{
A. A. GUNN AND J. C. GOULD \\ From the Department of Surgery, and Central Microbiological Laboratories, \\ Western General Hospital, Edinburgh
}

EDITORIAL SYNOPSIS The authors, by qualitative and quantitative assessment of the bacterial flora of the large bowel pre-operatively and at operation, have determined the sensitivities of the various organisms found. They have then endeavoured to discover the best agents to produce an effective reduction in the bacterial content of the intestine in patients about to undergo colonic surgery.

They state that in the majority of patients a combination of drugs such as framycetin, $2 \mathrm{~g}$., and ampicillin, 1 g., or neomycin, 2 g., plus bacitracin 100,000 units, per day will be effective.

The normal bacterial flora of the intestinal tract present a hazard of infection to the patient in any procedure which involves penetration or opening of the gut wall and the possible escape of contents. This hazard may be even further increased with organisms not normally commensal in the intestine. Thus it seems rational to attempt to reduce the bacterial content of the intestine when preparing patients for surgery so that the danger of contamination from this source with ensuing infection is reduced to a minimum.

Although detailed knowledge of the bowel flora is as yet incomplete it is evident that a large number of different species occur at different levels. Also the large number of microorganisms present in the lower intestine makes their removal difficult unless large quantities of substances with wide antibacterial spectra are available. For these reasons complete removal of bacteria from the lumen of the bowel is difficult if not impossible to achieve so that the term 'sterilization of the bowel' cannot be used in the strict meaning of the term. Rather is there suppression of the bowel flora to a greater or lesser degree which may affect some species more than others.

As yet there is no single antibacterial agent available which has an effect on all of the bacterial species likely to be present in the intestinal tract and therefore the best results have been obtained from the use of a combination of agents. Further it is not known whether all the bacterial species in the intestine are of equal importance in the problem of post-operative infection. The flora isolated from established post-operative infection resulting from contamination with bowel contents consists most frequently of Esch. coli, streptococci, bacteroides and Clostridia, but it may be that other flora play some part in the process of infection and therefore all species should be regarded as potentially dangerous and if possible suppressed.

A review of surgical treatment for carcinoma of the colon carried out in the Western General Hospital, Edinburgh, for the 10 years to 1956 showed that infection was responsible for $40 \%$ of mortality and $70 \%$ of morbidity. It was also clearly shown that infection originated either from contamination at operation or from subsequent leakage from the anastomosis. Thus any attempt to control the bacterial population must be not only preoperative but continue into the post-operative period. Quite apart from the risk of leakage from the anastomosis it has been shown that perfusion of an anastomosis increases the rate of healing (Cohn and Rives, 1956). Mechanical preparation of the bowel by enemata, a low-residue diet, and liquid paraffin helps to reduce the faecal content and to a certain extent the micro-flora. The choice of operation is planned to prevent unnecessary risk from infection; for example, immediate resection and anastomosis is not contemplated in a grossly obstructed large intestine. Furthermore, strict aseptic technique and gentle handling of the tissues are aimed at reducing the danger of infection from intestinal organisms at the time of operation. The use of antibacterial agents against the flora of the intestine has been shown to be a useful additional measure to such pre-operative preparations by a number of investigators (Firor, 1942; Poth, 1946; Fog, 1954; Cohn and Longacre, 1956; and Judd, 1961). However, there has been little detailed investigation of the selective reduction of the flora 
of the gut by single or combined antibacterial agents, nor of the effect of continuing post-operative administration of effective antibacterial agents in the lumen of the gut.

The most suitable antibacterial agent for supression of the bowel flora must not be toxic and be maintained in an effective concentration in the lumen of the intestine. Thus drugs which are not absorbed are more likely to be effective than those which are, and are less likely to have side effects by action on other tissues of the body. Low cost is of some importance since fairly large doses are required for periods of a week or more.

All the antibacterial agents which suppress the intestinal flora will create conditions suitable for the selection of strains of microorganisms which are resistant and which then multiply in the intestine, establish themselves and perhaps spread to other patients. In addition there is always present the danger of superinfection with antibiotic-resistant microorganisms in the environment, which in hospital include the staphylococcus, coliform bacilli, and monilia species. The possibility of pharmacological and immunological sensitization must also be taken into consideration in the selection of drugs.

The antibiotics which may be used for the suppression of the bowel flora are of two groups. The first group consists of topical antibacterial agents which are given by mouth and are relatively poorly absorbed from the intestine. Such are the sulphonamides which have been used in preoperative preparation of the bowel but fail to produce a regular or significant reduction in the bowel flora (Firor, 1942; Poth, 1946). They require some considerable time, e.g., four to five days, for any effect to become marked. In a controlled study, one of the authors showed that the incidence of infection following resection of the colon was $40 \%$ in two groups of patients, one receiving sulphonamide pre-operatively, also post-operative intramuscular penicillin and streptomycin, and the other receiving no antibiotics. Neomycin has also been widely used and large doses of several grams per day have been used over a short period of time, although pharmacological toxicity is fairly common (Cohn and Atik, 1961 ; Fog, 1954). In an experimental study using rats the most effective method of controlling infection following colon anastomosis was to give the drug (neomycin) orally before operation and into the lumen post-operatively (Gunn, Ch.M. thesis, in press). In a subsequent controlled clinical trial, post-operative intraluminar neomycin reduced the infection to $22 \%$ as against $40 \%$ in the control group (Gunn, Ch.M. thesis, in press).

More recently, framycetin and paromomycin have become increasingly popular in pre-operative preparation of the bowel. These antibiotics have a fairly broad spectrum of action against intestinal flora with relatively little toxicity and appear to be effective in reducing flora so that post-operative infection is reduced (Connell and Rouesselot, 1958; MacCabe, 1959; Horsburgh, 1961; Stratford and Dixson, 1964).

The second group are the systemic antibiotics which may be given either by mouth or parenterally and are absorbed from the gut and excreted into the gut following absorption. Some, such as the tetracyclines and chloramphenicol, have a fairly broad spectrum of activity; others, such as penicillin and streptomycin, have a relatively limited range of action against intestinal microorganisms (Phillips, Dearing and Waugh 1958). Thus the use of these systemic antibiotics results in a much more selective suppression of the gut flora and there tends to be overgrowth by other species, sometimes with undesirable side effects such as diarrhoea and colonization of antibiotic-resistant flora (Frisby, 1957).

The purpose of the present investigation was to assess the quality and quantity of the bacterial flora of the large bowel in patients coming for operation and to determine the sensitivity of the flora to a range of antibacterial agents likely to be useful in pre- and post-operative periods. Also, having obtained this information, to use it to determine in vitro the most efficient mixture of antibacterial agents for use in the individual patient. The chosen antibiotics were administered both pre-operatively and post-operatively and their effect measured by bacteriological examination of the bowel content at operation, and of the faeces in the post-operative period, by the clinical assessment of the progress of the patient and the incidence of infection.

\section{MATERIAL AND METHODS}

The patients selected were those admitted during a 12-month period from October 1962 to September 1963 for operation involving resection of the colon. The age and sex distribution is as shown in Table I, and the clinical diagnosis is given in Table II. The nature of the

\section{TABLE I}

AGE AND SEX DISTRIBUTION OF PATIENTS FOR COLON SURGERY

\begin{tabular}{lcccccccc} 
Sex & \multicolumn{9}{l}{ Age Group (yr.) } & Total \\
\cline { 2 - 8 } & $20-29$ & $30-39$ & $40-49$ & $50-59$ & $60-69$ & $70-79$ & \\
\hline Male & 0 & 1 & 0 & 8 & 8 & 3 & 20 \\
Female & 2 & 1 & 4 & 11 & 14 & 1 & 33 \\
Total & 2 & 2 & 4 & 19 & 22 & 4 & 53
\end{tabular}

operations carried out on these patients is given in Table III.

The microorganisms of the large bowel were assessed 
TABLE II

PATHOLOGICAL CONDITION OF PATIENTS FOR COLONIC SURGERY

\begin{tabular}{lccccc} 
Sex & Carcinoma & Diverticulitis $\begin{array}{c}\text { Ulcerative } \\
\text { Colitis }\end{array}$ & $\begin{array}{c}\text { Crohn's } \\
\text { Disease }\end{array}$ & Others \\
\hline Male & 8 & 9 & 1 & 2 & 0 \\
Female & 17 & 5 & 7 & 1 & 3 \\
Total & 25 & 14 & 8 & 3 & 3
\end{tabular}

TABLE III

NATURE OF OPERATIONS CARRIED OUT

\begin{tabular}{lc} 
Operation & $\begin{array}{c}\text { No. of } \\
\text { Cases }\end{array}$ \\
\hline Resection and anastomosis & 31 \\
Abdomino-perineal and procto-colectomy & 12 \\
Closure colostomy (Paul Mikulicz etc.) & 10
\end{tabular}

by examination of the faeces from each patient. Specimens of faeces were examined immediately after sampling into a pre-weighed Universal container and the weight obtained by difference. The faeces were emulsified in 5 volumes of physiological solution and standard loopfuls of the resulting suspension carrying $0.002 \mathrm{ml} .( \pm 0.0003$ ml.) (Urquhart and Gould, 1965) were transferred to the surface of suitable solid media which were incubated under both aerobic and anaerobic conditions. A selection of media was used including blood agar, MacConkey agar, brain heart infusion agar, and crystal violet blood agar, enabling the rapid identification of Streptococcus, Clostridium, Bacteroides, and the common coliform species.

Primary sensitivity tests were carried out on the faecal flora against penicillin, streptomycin, chloramphenicol, tetracycline, sulphonamide, neomycin, polymyxin, colomycin, framycetin, paromomycin, bacitracin, and ampicillin to measure any mutual antagonistic or synergistic effect that the mixture of microorganisms might have in association with the various antibiotics (Gould and Bowie, 1952).

Subculture sensitivity tests were carried out primarily to confirm the sensitivity of the organisms found on initial test and also to measure the bactericidal effect of antibiotics either singly or in combination. Only a limited amount of attention was given to detailed species identification so long as the main group of organisms present could be identified.

A quantitative estimation of the number of organisms was made by a modified loop technique and diluting a weighed sample of faeces (Gould, Bowie, and Cameron, 1953; Urquhart and Gould, 1965). The estimation of organisms was made to the nearest order of 10 and the logarithm of this figure was used to describe the amount of isolate of each species, e.g., one million organisms would be recorded as 6 .

The amount of topical antibiotics to be given to the patient was calculated on the basis of the number of each group of organisms isolated expressed as a logarithm of the viable count, the antibiotic sensitivity in micrograms or units per ml. (M.I.C.), and the approximate fluid volume of the bowel expressed in terms of fluid exchange during 24 hours, which was arbitrarily taken as 7 litres. This is shown in the following formula:-

$\begin{gathered}\begin{array}{c}\text { Amount of } \\ \text { antibiotic per } \\ \text { day }\end{array} \\ \text { (dose in } \mu \mathrm{g} .)\end{gathered} \quad \begin{gathered}\text { M.I.C. of } \\ \text { organism }\end{gathered} \times \begin{gathered}\log _{10} \text { of } \\ \text { viable count }\end{gathered} \times \begin{gathered}\text { fluid volume } \\ \text { of intestine } \\ \text { in ml. }\end{gathered}$

For example, if Esch. coli was isolated at $10^{8} / \mathrm{ml}$. and had a M.I.C. of $20 \mu \mathrm{g} . / \mathrm{ml}$. to framycetin, and streptococci were isolated at $10^{\circ} / \mathrm{ml}$. with M.I.C. of $10 \mu \mathrm{g} . / \mathrm{ml}$. to ampicillin, the dose of antibiotic given would equal $20 \times 8 \times 7,000=1.02 \mathrm{~g}$. of framycetin/day, $\times 10 \times 9$ $\times 7,000=0 \cdot 6 \mathrm{~g}$. of ampicillin/day.

This assumes that all of the antibiotic is retained within the lumen of the gut and also that the number of organisms is a significant factor because of their dilution over a large surface area of the bowel mucosa. It is accepted that the validity of this calculation will not apply to agents which are largely absorbed from the upper bowel, though a proportion of such drugs will be reexcreted into the bowel.

Where the operation involved resection of the rectum, a Portex (1 mm. lumen) tube was placed in the perineal cavity and brought out through the abdominal wound. In patients receiving resection and anastomosis an antibiotic was delivered in the same divided daily dose by means of an intraluminar ( $1 \mathrm{~mm}$. lumen) tube for three days, and by mouth on the third, fourth, and fifth day, the tube being withdrawn on the fourth day. In these patients receiving excision of the rectum the antibiotic was given by the tube for the five days and then withdrawn.

Examination of the flora in the lumen of the gut was made on the material taken at the time of operation in a manner similar to that described above for the preoperative faecal specimen. The post-operative faecal specimen was similarly examined to assess the quantity and quality of the species present following cessation of antibiotic treatment. Where possible, follow-up examinations on specimens of faeces were carried out to assess the degree and rate of bacterial recolonization.

A punch card system was used to assess the clinical results. The patients were all admitted to the one surgical charge in the hospital. The question of a control group was discussed but it was decided to omit this on ethical grounds as the risk to the patient had previously been clearly shown (Gunn, Ch.M. thesis, in press).

\section{BACTERIOLOGICAL RESULTS}

Bacteriological examination of faeces was carried out in 70 patients pre-operatively, but as 20 of these could not be clinically assessed at later stages they were excluded from the trial. The remaining 50 patients included 20 males and 30 females. In two, two separate operations were carried out which involved separate bacteriological assessments and therefore the results are quoted as applying to $\mathbf{5 2}$ cases. In only 40 patients was full pre- and postoperative bacteriological examination carried out.

The bacteriological assessment of the results of antibiotic treatment was made on the degree of 
reduction of the total flora as measured in operation specimens compared with the pre-operative specimen, and recorded as the difference in the logarithm of a number of organisms isolated per gram of faeces or bowel content, and also on the appearance of flora not found in the pre-operative specimen. Bacteriological success was assumed when there was a reduction in the quantity of the flora greater than $10^{4}$ times. A moderate bacteriological effect was recorded when the reduction was between 10 and 1,000 -fold and cases with less than a tenfold reduction were recorded as having had no bacteriological effect. Table IV shows the results in the 40 cases where bacteriological assessment was complete. The greatest reduction in flora was $10^{9}$ times, and in 17 cases reduction was greater than $10^{8}$ times: in a further eight cases reduction was $10^{7}$ times, in two $10^{3}$ times, and in four $10^{3}$ times. In five cases there was no measurable bacteriological effect.

\section{TABLE IV}

CLINICAL AND BACTERIOLOGICAL RESULTS IN THE ANTIBIOTIC-TREATED CASES

Clinical Assessment Bacteriological Assessment by Reduction of Bowel Flora

\begin{tabular}{lll}
\hline $10^{4}$ Times & $10-10^{3}$ & 10 Times No \\
Success & Moderate & Effect \\
& Effect &
\end{tabular}

Success 33

Total 39

26
4
30

30

3

4

The examination of the flora present at the time of operation, i.e., 48 hours after commencement of antibiotic treatment, showed replacement of the pre-operative flora to a varying degree with other species in 21 cases (Table V). Such replacement was somewhat more frequent on examination of postoperative faeces as is also shown in Table $\mathrm{V}$ where 27 cases showed such change.

\section{TABLE V}

ISOLATION OF REPLACEMENT MICROORGANISMS FROM PATIENTS AT OPERATION AND IN THE POST-OPERATIVE PERIOD

Organism

\begin{tabular}{|c|c|c|}
\hline easts & $\begin{array}{l}\text { Staphylo- } \\
\text { cocci }\end{array}$ & $\begin{array}{l}\text { Pseudo- } \\
\text { monas }\end{array}$ \\
\hline
\end{tabular}

At operation

No. of case

$16 \quad 2$

2

$\begin{array}{rr}1 & 1 \\ 10^{7} & 10^{4}\end{array}$

Post-operative

No. of cases

$10^{2-7} \quad 10^{4-6}$

$10^{4}$

$10^{2}$

$10^{4}$

Range per $\mathrm{g}$.

$17 \quad 13$

2

$\begin{array}{cc}6 & 4 \\ 10^{6-7} & 10^{5-7}\end{array}$

In the majority of the patients, normal intestinal organisms such as Esch. coli, Streptococcus, Clostridia, and Bacteroides recolonized in the later postoperative period although a few cases still had staphylococci and yeasts present in relatively small numbers. There was, however, a tendency to recolonize with strains of Esch. coli and Streptococcus which were more resistant to antibiotics such as ampicillin, streptomycin, tetracycline, and more occasionally chloramphenicol, than the strains isolated pre-operatively. In no case was resistance to the antibiotics used for pre-and post-operative treatment observed. It is not known whether these antibiotic-resistant strains were the same or different in their biological characters from the pre-operative flora.

The majority of the patients were treated with two or more antibiotics in combination as the flora isolated from the pre-operative specimens could not be controlled in vitro by a single antibiotic except in five patients, three of whom received framycetin and two neomycin. In one patient receiving neomycin there was no effect upon the bowel flora but in the other four there was a moderate effect. Two of the cases treated with framycetin in high dosage (4 or more grams per day) were bacteriological successes and one was a failure with no bacteriological effect.

The most commonly indicated mixtures of antibiotics were framycetin with ampicillin or neomycin with bacitracin. Occasionally colomycin or polymyxin would be indicated for the presence of Pseudomonas, and in a few cases erythromycin was indicated for the control of resistant streptococci. In a number of cases sulphonamides were active in vitro against Clostridia and other anaerobic flora not controlled by framycetin, neomycin, or paromomycin and were used as an alternative to penicillin or bacitracin. No particular combination of drugs was associated with failure to reduce the intestinal flora by less than $10^{4}$ times and it must be assumed that the individual nature of the flora in these patients was the major factor involved in preventing reduction in the flora.

\section{CLINICAL RESULTS}

The clinical results were available in all 53 cases and may be compared with the bacteriological results up to and including the time of operation. Among the 53 cases available for comparison, infection occurred in seven. The relationship of these cases to the underlying pathology is shown in Table VI. The

TABLE VI

INCIDENCE OF INFECTION RELATED TO PATHOLOGICAL CONDITION

\begin{tabular}{lcc} 
Pathology & No. of Cases & $\begin{array}{l}\text { Number with } \\
\text { Infection (\%) }\end{array}$ \\
\hline Carcinoma & 25 & $2(4)$ \\
Diverticulitis & 14 & $2(14)$ \\
Ulcerative colitis & 8 & $3(38)$
\end{tabular}


pathological diagnosis also influenced the type of operation that was required for the individual patient and it will be seen from Table VII that

\section{TABLE VII}

INCIDENCE OF INFECTION RELATED TO OPERATIVE PROCEDURE

\begin{tabular}{lccc} 
Operation & $\begin{array}{l}\text { No } \\
\text { Infection }\end{array}$ & Infection & $\begin{array}{l}\text { Total No. } \\
\text { of } \\
\text { Operations }\end{array}$ \\
\hline With anastomosis & 33 & 3 & 36 \\
With excision of rectum & 8 & 4 & 12 \\
Others & 5 & 0 & 5
\end{tabular}

operations which included excision of the rectum had a higher incidence of infection.

Thus the overall incidence of infection in this preliminary series was seven out of 53 and for operation for carcinoma two out of 25 cases. This result is a considerable improvement over those obtained in a trial previously mentioned. The failures are detailed in Table VIII, and several points arise from their consideration. The first is the problem involved with excision of the rectum as in procto-colectomy or abdomino-perineal resection, both resulting in a perineal space. It has been our practice to close the perineum around the Foley catheter and if this is not possible to leave a pack in the space. The use of abdominal perineal perfusion with antibiotics has reduced infection but as this space takes time to fill up a certain incidence of late infection is unavoidable unless a more satisfactory method becomes available.

Technical errors can be reduced to a minimum but not entirely excluded and the third case is a failure in point; the anastomosis disrupted due to poor vascularity and was under considerable tension. Antibiotics obviously cannot be expected to counteract major deficiencies in blood supply but could reduce the morbidity of such gross contamination of the peritoneum with bowel flora (Cohn and Rives, 1956). In a third case failure was due to an abscess between the colon and the bladder resulting from diverticulitis, and a fistula developed. Although the intestinal flora had been markedly reduced the abscess had not been affected to the same degree and infection developed. Unfortunately in this case some post-operative bleeding occurred into the anastomotic area which became infected with organisms from the abscess. In retrospect it would have been wiser to have staged this resection rather than to carry out a one-stage operation.

The two instances of staphylococcal infection of the wound did not reflect the presence of this infection in the bowel on account of selection or superinfection. No staphylococci were isolated from the intestine of these patients and it must be presumed that the infection came from the patient's skin or his environment.

Human error is illustrated by the second failure where the patient was prepared for resection by pre-operative oral administration of antibiotics despite the presence of a transverse colostomy.

\section{DISCUSSION}

Selective antibiotic cover for colonic surgery aims at a reduction in the morbidity of infection which still remains the major problem in this field. Correct selection of antibiotics is accepted as being correct in principle and should in our opinion be applied wherever there is an indication for the use of these agents.

The need for the use of antibacterial agents to prepare cases for colonic surgery has been established by many workers. However, it must be emphasized that antibiotics are not an alternative to good mechanical preparation, the correct type of operation, and meticulous technique. They merely assist in a more successful outcome from operations in which care and technique have been applied and are therefore desirable additional measures.

In this series the method of selection of antibiotics has been given, which involves a detailed quantitative and qualitative assessment of the intestinal flora, and the amount of antibiotics given to each patient has been calculated in a manner which although

TABLE VIII

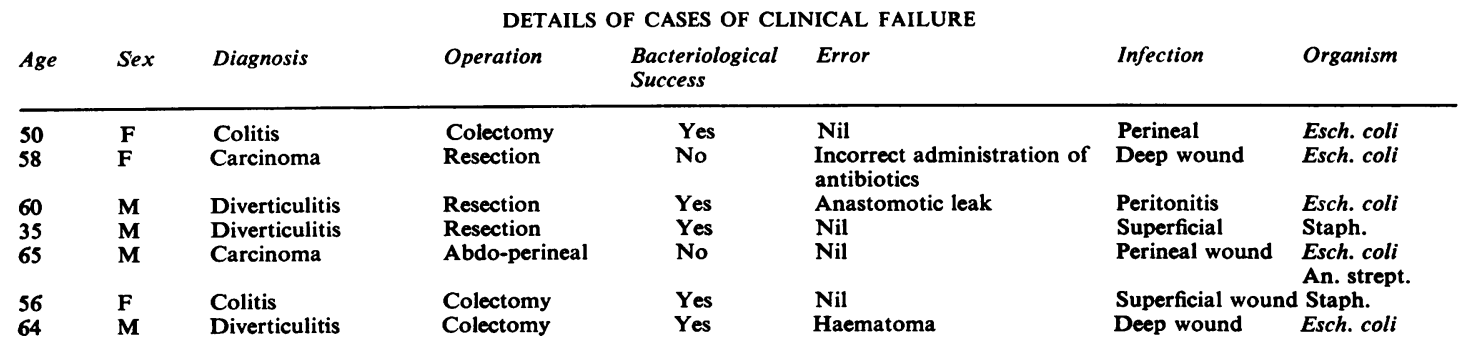


approximate, seems to be effective as borne out by the success in reducing the faecal flora with moderate amounts of antibiotics. Further investigation is required to determine how best to increase the likelihood of a significant reduction of the intestinal flora in all cases, since it does not appear to be entirely related to the amount of available antibiotic in the gut. It is obvious that individual variations in the absorption and the excretion of antibiotics will affect the available amount, but local conditions within the lumen of the bowel may also have a considerable effect upon the suppression of different species. The method of administration of the antibiotic and the results emphasize the importance of continuing antibiotic cover well into the postoperative period, and to this end the use of the intraluminal tube or local instillation in cases of abdomino-perineal operation seems to be of more value. The previously recognized dangers and drawbacks of antibiotic treatment of the bowel have not been proved in this series, and, while staphylococci, yeasts and species of Gram-negative bacteria, such as Klebsiella, Pseudomonas, and Proteus, occur during and immediately after the exhibition of antibiotics in approximately half of our cases, the number of these organisms present was relatively small and appears to have no clinical importance. Recolonization by strains of coliform and streptococci more resistant to the systemic antibiotics which were not used in this investigation is of interest and may indicate the result of contamination of the gut of these patients with strains from the hospital environment and this may present a problem to be studied further. The results so far do not indicate how long such antibiotic-resistant flora remain in the gut of these patients.

An additional danger in cancer surgery is the increased risk of implantation of tumour at the anastomosis when the bowel has been rendered relatively free of microorganisms (Vink, 1954; Cohn, and Atik, 1960, 1961). We are well aware of the dangers of tumour dissemination, and suitable precautions, both technical and involving the use of antimitotic drugs, have been used for eight years. Despite our interest in the problem of bowel sterility the incidence of anastomotic recurrence is $7.5 \%$ as compared with $16 \%$ for the period before 1957 . These figures are similar to those from other centres (Morgan, 1950; Goligher, 1958). Finally it was realized that in many centres there may not be adequate bacteriological facilities to enable detailed examination of patients as in this work. It can be stated that in the majority of patients, a combination of drugs such as framycetin, $2 \mathrm{~g}$. and ampicillin, $1 \mathrm{~g}$., or neomycin, 2 g. plus bacitracin 100,000 units, per day will be effective.

\section{SUMMARY}

A method of selection of antibiotics for preoperative bowel sterilization is outlined, based on detailed faecal culture.

The antibiotics were administered pre-operatively by mouth and post-operatively into the bowel lumen.

A high degree of suppression of the bacterial flora resulted with relatively small dosage of antibiotics.

The incidence of infection was low.

Yeasts, staphylococci, and other transient abnormal flora appeared frequently but were of no clinical importance.

We wish to thank Mr. C. W. A. Falconer, F.R.C.S., and the other surgeons and physicians who have cooperated in the care of these patients, and also Mr. Eric Kerr, F.I.M.L.T., for technical assistance.

\section{REFERENCES}

Cohn, I., and Atik, M. (1960). The influence of antibiotics on the spread of tumors of the colon. Ann. Surg., 151, 917-929.

(1961). Intestinal antispesis and the spread of tumors of the colon. Amer. J. Surg., 101, 3-6.

— and Longacre, A. B. (1956). Tetracycline (achromycin)-neomycin for preoperative colon preparation. Arch. Surg., 72, 371-376.

and Rives, J. D. (1956). Protection of colonic anastomoses with antibiotics. Ann. Surg., 144, 738-752.

Connell, J. F. Jr., and Rousselot, L. M. (1958). Preliminary studies on a new intestinal bactericide-soframycin. Surgery, 44, 447-452.

Firor, W. M. (1942). Intestinal antisepsis with sulfonamides. Ann. Surg., 115, 829-832.

Fog, C. V. M. (1954). Studies on reduction of intestinal flora. Arch. Surg., 69, 858-869.

Frisby, B. R. (1957). Staphylococcal diarrhoea, with special reference to its epidemiology and prevention. In Hospital Coccal Infections: a Symposium arranged by the Assoc. Clin. Path., and the Med. Res. Council, edited by R. E. O. Williams and R. A. Shooter. pp. 8-12. Assoc. Clin. Path., Reading.

Goligher, J. C. (1958). Preservation of the anal sphincters in the radical treatment of rectal cancer. Ann. roy. Coll. Surg. Engl., 22, 311-329.

Gould, J. C., and Bowie, J. H. (1952). The determination of bacterial sensitivity to antibiotics. Edinb. med. J., 59, 178-199.

$\longrightarrow$, and Cameron, J. D. S. (1953). Dosage of antibiotics: relation between the in-vitro and in-vivo concentrations effective in urinary-tract infections. Lancet, 1, 361-364.

Gunn, A. A. Carcinoma of the colon. Ch.M. thesis, in the press.

Horsburgh, A. G. (1961). Framycetin sulphate (Soframycin) as a pre-operative bowel-sterilizing agent. Gut, 2, 51-52.

Judd, E. S. (1961). The risk of surgery of the colon: current trends in hospital mortality rates. Proc. Mayo Clin., 36, 492-503.

MacCabe, A. F. (1959). Framycetin. Practitioner, 182, 628-634.

Morgan, C. N. (1950). Discussion on conservative resection in carcinoma of the rectum. Proc. roy. Soc. Med., 43, 701-705.

Phillips, D. F., Dearing, W. H., and Waugh, J. M. (1958). Comparison of complications following intestinal surgery after oral and parenteral antibiotic preparation. Surg. Gynec. Obstet., 106, 145-152.

Poth, E. J. (1946). Sulfasuzidine and Sulfathalidine. Texas Rep. Biol. Med., 4, 68-102.

Stratford, B. C., and Dixson, S. (1964). Intestinal asepsis with neomycin and framycetin: a comparative study. Med. J. Aust., 1, 74-79.

Urquhart, G., and Gould, J. C. (1965). A simplified technique for counting bacteria in urine and other fluids. J. clin. Path., 18, 490.

Vink, M. (1954). Local recurrence of cancer in the large bowel: the role of implantation metastases and bowel disinfection. Brit. J. Surg., 41, 431-433. 